\title{
Patient perspectives on peer support for adults with type I diabetes: a need for diabetes-specific social capital
}

This article was published in the following Dove Press journal:

Patient Preference and Adherence

2 August 2016

Number of times this article has been viewed

\author{
Lene E Joensen' \\ Tine Filges ${ }^{2}$ \\ Ingrid Willaing' \\ 'Health Promotion Research, Steno \\ Diabetes Center, Gentofte, ${ }^{2}$ Filges \\ Analysis, Hellerup, Denmark
}

Aim: To explore the function of peer support from the perspective of adults with type 1 diabetes in Denmark.

Methods: The study population consisted of 20 adults with type 1 diabetes. The sample was diverse in relation to educational background, age, sex, and cohabitation status. Inspired by action research, several methods and perspectives on peer support were explored and tested. Workshops and group and individual interviews were performed. Systematic text condensation was used to analyze data, supplemented with theory-based interpretive analysis.

Results: Adults with type 1 diabetes found peer support highly relevant to reduce a burdensome feeling of diabetes-specific loneliness. Peer support showed potential to create diabetesspecific social capital not only by creating reciprocal social support between peers but also, more importantly, by creating space for genuine trust and a feeling of communality. There was a widespread feeling of the pervasive impact of diabetes on daily life and thus the relevance of discussing all aspects of life. However, participants perceived peer support as particularly relevant in relation to big changes in life, for example, in family life, at work, or through treatment events such as getting an insulin pump.

Conclusion: Peer support programs focusing on creating and establishing diabetes-specific social capital using participatory approaches seem highly relevant among adults with type 1 diabetes. Content, methods, and effects of peer support need further exploration in collaboration with adults with type 1 diabetes.

Keywords: type 1 diabetes mellitus, adult, psychosocial support systems, patient preferences, peer support, diabetes-specific social capital, diabetes-specific loneliness

\section{Introduction}

Managing their disease is a constant task for people with type 1 diabetes, and most daily management occurs without the involvement of health care professionals. People with type 1 diabetes often experience psychosocial problems such as anxiety and diabetes distress, ${ }^{1,2}$ and previous studies have indicated that lack of social support is associated with lower psychological well-being, as well as difficulties in managing diabetes and poorer glycemic control, in people with type 1 diabetes. ${ }^{3,4}$

The link between a lack of social support and poor physical and mental health is well established. ${ }^{5,6}$ Positive social support includes emotional, instrumental, and informational support and influences health and well-being through a variety of pathways, for example, by improving health behaviors, enhancing self-esteem with regard to performing self-care activities, and reducing distress. ${ }^{7}$ Previous research has shown that high diabetes-specific social support is particularly associated with lower 
diabetes distress. ${ }^{8}$ However, knowledge is lacking about methods and interventions to enhance diabetes-specific social support among adults with type 1 diabetes.

A promising way to enhance diabetes-specific social support is through peer support; studies among adults with diabetes have found peer support to be an effective method to provide emotional support for ongoing selfmanagement. ${ }^{9-12}$ However, most studies focus on type 2 diabetes, and little is known about peer support among adults with type 1 diabetes. ${ }^{13}$

Peer support in health care is defined as a method to create and strengthen social relationships, thereby improving and maintaining good health and well-being., ${ }^{9,14}$ The key functions of peer support have been identified by Peers for Progress - a program dedicated to promote evidence-based peer support as a key part of health care and prevention. ${ }^{15}$ The key functions are, 1) assistance in daily management, 2) social and emotional support, 3) linkage to clinical care and community resources, and 4) ongoing support of chronic disease management. ${ }^{16}$ Peer support creates a unique opportunity to reflect on daily life through sharing experiential knowledge. ${ }^{9,14,17}$ However, the literature on diabetes-specific peer support currently addresses a wide range of peer interactions and interventions, ${ }^{17}$ and the evidence is insufficient to determine which types of peer interactions, elements, and interventions are most applicable to and effective in type 1 diabetes. Furthermore, a 2013 review of diabetes-specific peer support literature revealed a tendency to confound diabetes-specific peer support with educational or selfmanagement programs building on health professionals' understanding of support. ${ }^{17}$ Similarly, a frequent argument for the provision of diabetes-specific peer support is the growing number of people who need support and health care resources. ${ }^{13,18}$ This argument emphasizes peer support in lieu of professional care and does not stress the qualities of peer support as promoting and strengthening reciprocal social support between peers.

Although studies of diabetes-specific peer support generally focus on interactions between and support among people with diabetes, little is known about how members of the target group experience peer support. The aim of this study was to explore the function of peer support from the perspective of adults with type 1 diabetes in Denmark.

\section{Methods}

\section{Study population}

Twenty adults with type 1 diabetes participated in the study. Using convenience sampling, eleven adults were recruited from a specialized diabetes clinic in greater Copenhagen, Denmark, and nine adults were recruited from four different specialist diabetes clinics in the Central Region of Denmark. Participants were recruited through mailed invitations to individuals participating in a related study and notices on Danish Internet forums for people with type 1 diabetes posted by a study participant (Tine Filges, co-author). All adults with type 1 diabetes were eligible for participation, but the specific participants were selected to ensure a diverse sample in relation to educational background, age, sex, and cohabitation status (Table 1).

\section{Data collection}

We collected data on participants' perspectives on peer support during workshops and interviews. Inspired by action research, ${ }^{19}$ we explored the function of peer support by evaluating different peer support methods at the workshops (Table 2). For example, we evaluated dialogue tools in the peer groups. Different probes were also used to prompt immediate reflection on peer support among participants, for example, presenting peer support scenario cartoons. Group discussions and individual interviews were guided by facilitating questions related to the specific aims and tools used in the workshops (Table 2). The investigation of participants' view on peer support included exploring relevant topics to discuss with peers, the purpose of peer support, preferred characteristics of peer supporters, and preferred format of peer support. Workshops lasted 2.5 hours.

One workshop (nine participants) was held in the Central Region of Denmark. The group of eleven adults with type 1 diabetes recruited from Steno Diabetes Center, the specialized diabetes clinic in greater Copenhagen, participated in five workshops between January and November 2013. The number of workshops in which participants took part varied from five (three participants) to one (one participant). To ensure that all participants' views were incorporated into the data, we conducted individual interviews with participants who did

Table I Participant characteristics

\begin{tabular}{lll}
\hline & $\begin{array}{l}\text { Capital region } \\
\text { of Denmark } \\
(\mathbf{n}=I \mathbf{I})\end{array}$ & $\begin{array}{l}\text { Central } \\
\text { Denmark region } \\
(\mathbf{n}=9)\end{array}$ \\
\hline Age, mean (range), years & $46(3 \mathrm{I}-62)$ & $45(3 \mathrm{I}-56)$ \\
Diabetes duration, mean (range), & $23(\mathrm{I}-49)$ & $25(\mathrm{I}-30)$ \\
years & & \\
Women (n) & 8 & 6 \\
Employed (n) & 9 & 6 \\
Married/living with a partner (n) & 9 & $\mathrm{~N} / \mathrm{A}$ \\
\hline
\end{tabular}

Abbreviation: N/A, not available. 
Table 2 Types of data generated in workshops and individual interviews

\begin{tabular}{|c|c|c|c|c|}
\hline & Aim & Participants (n) & Methods & Data \\
\hline Workshop I & $\begin{array}{l}\text { To introduce the concept of peer } \\
\text { support and initiate dialogue on } \\
\text { participants' views of peer support }\end{array}$ & II & $\begin{array}{l}\text { Introduction by researcher and people with type } \\
\text { I diabetes: } \\
\text { The significance of social support } \\
\text { Experiences with and ideas of peer support } \\
\text { Group discussion }\end{array}$ & $\begin{array}{l}\text { Transcribed group } \\
\text { discussions } \\
\text { Minutes } \\
\text { Field notes }\end{array}$ \\
\hline Workshop 2 & $\begin{array}{l}\text { To identify and discuss peer } \\
\text { support needs }\end{array}$ & 8 & $\begin{array}{l}\text { Exercise: prioritizing themes of peer support needs } \\
\text { Exercise: preferred characteristics of a peer } \\
\text { supporter } \\
\text { Discussions in pairs } \\
\text { Group discussions }\end{array}$ & $\begin{array}{l}\text { Transcribed group } \\
\text { discussions } \\
\text { Minutes } \\
\text { Field notes } \\
\text { Notes from participants }\end{array}$ \\
\hline $\begin{array}{l}\text { Individual } \\
\text { interviews }\end{array}$ & To identify peer support needs & 4 & $\begin{array}{l}\text { Exercise: prioritizing themes of peer support needs } \\
\text { Exercise: preferred characteristics of a peer } \\
\text { supporter } \\
\text { Semi-structured individual interviews }\end{array}$ & $\begin{array}{l}\text { Transcribed individual } \\
\text { interviews }\end{array}$ \\
\hline Workshop 3 & $\begin{array}{l}\text { To validate results from } \\
\text { workshops I and } 2 \\
\text { To identify and discuss preferences } \\
\text { for peer support methods }\end{array}$ & 8 & $\begin{array}{l}\text { Group discussions based on presentation of } \\
\text { themes and peer support characteristics by } \\
\text { researcher } \\
\text { Presentation of peer support scenario cartoons, } \\
\text { rating, and semi-structured group discussions }\end{array}$ & $\begin{array}{l}\text { Transcribed group } \\
\text { discussions } \\
\text { Minutes } \\
\text { Field notes } \\
\text { Notes from participants }\end{array}$ \\
\hline $\begin{array}{l}\text { Individual } \\
\text { interviews }\end{array}$ & $\begin{array}{l}\text { To validate results from } \\
\text { workshops I and } 2 \\
\text { To identify and discuss preferences } \\
\text { for peer support methods }\end{array}$ & 2 & $\begin{array}{l}\text { Semi-structured individual interview based } \\
\text { on presentation of themes and peer support } \\
\text { characteristics by researcher } \\
\text { Presentation of peer support scenario cartoons, } \\
\text { rating, and individual interview }\end{array}$ & $\begin{array}{l}\text { Transcribed individual } \\
\text { interviews }\end{array}$ \\
\hline Workshop 4 & $\begin{array}{l}\text { To explore the creation of } \\
\text { person-centered dialogue } \\
\text { between peers }\end{array}$ & 7 & $\begin{array}{l}\text { Tests of dialogue tools } \\
\text { Discussion in pairs } \\
\text { Group discussions }\end{array}$ & $\begin{array}{l}\text { Transcribed group } \\
\text { discussions } \\
\text { Minutes } \\
\text { Field notes } \\
\text { Notes from participants }\end{array}$ \\
\hline Workshop 5 & $\begin{array}{l}\text { To validate workshops } \mathrm{I}-4 \text { in } \\
\text { another population and setting }\end{array}$ & 9 & $\begin{array}{l}\text { Exercise: prioritizing themes of peer support needs } \\
\text { Exercise: peer versus professional supporter } \\
\text { characteristics } \\
\text { Tests of dialogue tools } \\
\text { Group discussions }\end{array}$ & $\begin{array}{l}\text { Transcribed group } \\
\text { discussions } \\
\text { Minutes } \\
\text { Field notes } \\
\text { Notes from participants }\end{array}$ \\
\hline Workshop 6 & $\begin{array}{l}\text { To validate the constructs of } \\
\text { "diabetes-specific loneliness" and } \\
\text { "diabetes-specific social capital" } \\
\text { (in lay terminology) }\end{array}$ & 8 & Group discussions & $\begin{array}{l}\text { Transcribed group } \\
\text { discussions } \\
\text { Minutes }\end{array}$ \\
\hline
\end{tabular}

not participate in all workshops; interviews lasted $\sim 1$ hour. Data consisted of field notes, minutes, and transcribed group discussions from all six workshops, notes and completed exercises from workshop participants, and transcriptions from six individual interviews.

One researcher facilitated each workshop, and two or three researchers observed small group workshop and plenary sessions. One participant (Tine Filges, co-author) who was competent at research participated in workshop planning and facilitated selected exercises. Written informed consent was obtained from all participants. The study was approved by the Danish Data Protection Agency.

\section{Qualitative analyses}

Data were analyzed by systematic text condensation. ${ }^{20}$ Initially, we read all data to obtain a general impression of important preliminary themes. All written text was then divided into units of meaning, and related units were sorted into groups representing subthemes. A final step was to cluster related subthemes to structure data into main themes. ${ }^{20}$ While clustering subthemes into main themes, we used the constructs of social capital and loneliness as an interpretative framework. ${ }^{21,22}$ The choice of these constructs was not predetermined but emerged from the empirical subthemes. Figure 1 depicts the analytic approach. 


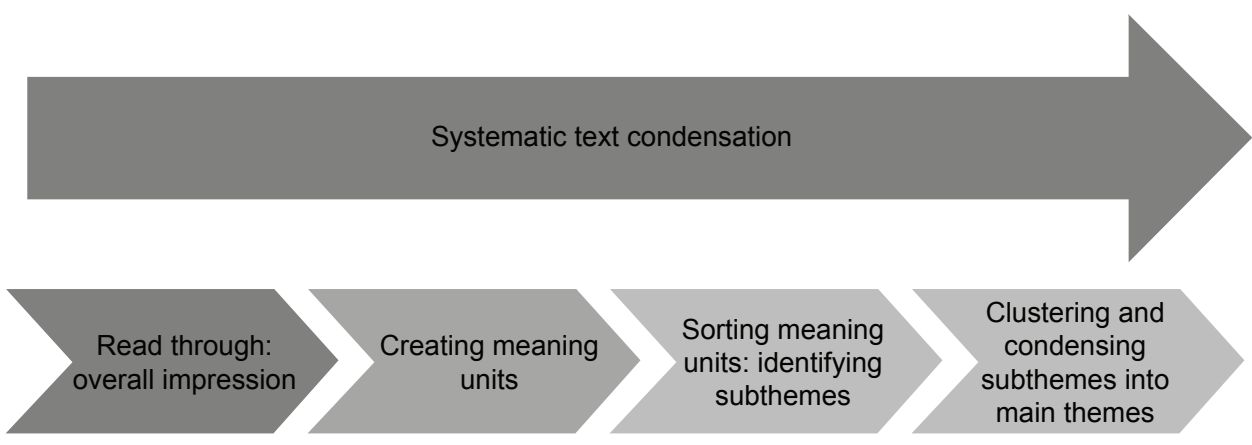

Figure I Analytic approach.

Analyses were performed by the first and last authors, both of whom were present during all workshops. To ensure transparency and validity, the subthemes were presented to workshop participants; their comments and perspectives were incorporated into the analysis. Researchers involved in the workshops also commented on the subthemes.

\section{Results}

\section{Diabetes-specific loneliness}

Among participants, a widespread feeling existed that diabetes was pervasive throughout all aspects of life, and it was thus relevant to discuss diabetes with peers in relation to all aspects of life with type 1 diabetes. In general, participants' descriptions of the function of peer support were connected to a feeling of loneliness related to their diabetes. Participants pointed out their experiences of dissatisfaction with social relations with regard to diabetes that included, 1) being on one's own, 2) lack of connectedness and communality, and 3) lack of feeling understood (Table 3).

\section{Being on one's own}

Participants expressed that they felt "on their own" not only in relation to specific situations, such as travel planning, but also in general in daily life with diabetes, for example, "having no one to talk to" (male, age 35 years) and "having to make your own experiments on how to live well with diabetes" (male, age 46 years). Participants described how questions, feelings, and uncertainties arise in daily life with diabetes; they felt they had to handle most things by themselves. A woman diagnosed in adulthood expressed the feeling of being on her own:

No matter how good and well-meaning a health care professional is, it is in your everyday life that you face these problems, or challenges I would rather call them, and it is actually here that you need someone to talk to about your day and other things. So, I have to deal with all my thoughts and feelings on my own. Of course I can share these things with my friends and family, but they can ... they can only listen, not engage in a dialogue. [Female, age 48 years]

Another woman from the Central Region of Denmark stated:

I don't have anyone in my everyday life ... I have a thing with counting carbohydrates - it would be amazing to come into contact with someone and ask them about how do you do it? and does it have any benefits for you? ... and so on. [Age 56 years]

Feeling on one's own also included the feeling of not having enough time with health care professionals.

Table 3 Main themes based on empirical findings

\begin{tabular}{|c|c|}
\hline Main themes & Empirical subthemes \\
\hline \multicolumn{2}{|l|}{ Diabetes-specific loneliness } \\
\hline Being on one's own & $\begin{array}{l}\text { Having no one to talk to about } \\
\text { diabetes } \\
\text { Experimenting individually about how } \\
\text { to live well with diabetes in daily life } \\
\text { Lacking time with health professionals }\end{array}$ \\
\hline $\begin{array}{l}\text { Lack of connectedness and } \\
\text { communality }\end{array}$ & $\begin{array}{l}\text { Feeling different } \\
\text { Feeling less worthy/burdensome } \\
\text { Feeling shoved out of community }\end{array}$ \\
\hline Lack of feeling understood & $\begin{array}{l}\text { No real dialogue about diabetes } \\
\text { No understanding of how difficult it is } \\
\text { to live with diabetes }\end{array}$ \\
\hline \multicolumn{2}{|l|}{ Diabetes-specific social capital } \\
\hline Experience sharing & $\begin{array}{l}\text { Sharing real-life experiences } \\
\text { No professional knowledge }\end{array}$ \\
\hline Cohesion and collectiveness & $\begin{array}{l}\text { Experiencing type I diabetes as normal } \\
\text { Feeling mutual understanding } \\
\text { Being able to mirror oneself in others }\end{array}$ \\
\hline Trust and confidence & $\begin{array}{l}\text { Feeling safe } \\
\text { Trusting others } \\
\text { Having confidentiality }\end{array}$ \\
\hline $\begin{array}{l}\text { Reciprocity and social } \\
\text { participation }\end{array}$ & $\begin{array}{l}\text { Mutual trust and support } \\
\text { Necessary similarities and/or benefits } \\
\text { of being different } \\
\text { Wanting to help and create possibilities } \\
\text { for others with type I diabetes }\end{array}$ \\
\hline
\end{tabular}




\section{Lack of connectedness and communality}

Participants described feeling "excluded from society", "different than the rest", and "worth less than others". One woman expressed the feeling of "being second-rate" and "being shoved out of the community" in relation to employment: "When there's an economic crisis like we have now, with lots of people unemployed, then having diabetes is a disadvantage, it becomes a kind of sorting mechanism" (age 60 years). She did not inform employers about her diabetes when applying for a new job. In a similar vein, other participants described feeling uncomfortable with others knowing about their diabetes. One woman expressed feeling that society requires people with type 1 diabetes to deal with diabetes in such a way that they do not become a burden. A related comment from another participant described feeling that health care professionals judged her as a number:

... when you consult the professional you have 15 minutes and it ... you are just a social security number ... and the lower your average blood sugar level is the better. It's even fine if your blood sugar is a little low at times. That will lower the average [of the clinic's overall population] slightly. It doesn't matter that you are shaking a bit, it's good for your Hba1c! [Female, age 35 years]

Other participants expressed feeling less worthy. A 35-year-old man stated: "I don't think there are any girls who should content themselves with me. I feel like I am a sickness and a burden to people".

\section{Lack of feeling understood}

Participants spoke frequently of experiences of lack of understanding from friends, family, health professionals, and society. A participant expressed the lack of understanding by society very explicitly:

If there was more recognition in our society, that there is also a lot going on in your head when you get the disease, it would be easier to talk about. I mean, the majority of people seem to be of the opinion that as long as you get your injections you'll be fine ... but it's not quite like that. [Male, age 35 years]

Several participants felt that "friends and family can only listen" to their experiences of living with diabetes but cannot "really understand". Participants lacked what they called "a real dialogue about diabetes" with family, friends, and colleagues. Participants also stated that they found it difficult or impossible to have a real dialogue about daily life with diabetes and to feel understood by health care professionals, even though the latter had relevant and important clinical knowledge. However, participants also stated that health care professionals often grasped problems during consultations.

\section{Diabetes-specific social capital}

Participants' views of relevant peer support could be interpreted as a need for diabetes-specific social capital. The need for diabetes-specific social capital included perceptions of the importance of peer support and its ability to create experience sharing, cohesion and collectiveness, trust and confidence, and reciprocity and social participation related to life with type 1 diabetes (Table 3 ).

\section{Experience sharing}

Participants were very clear in distinguishing between experiences and knowledge when they talked about their need for peer support. As an example, one participant stated:

We don't like the word "expert" [in relation to peer support].

We talk about experience. We are not experts - we are experienced. One's expertise from living with diabetes cannot necessarily be applied to another person with type 1 diabetes. We live different lives. You cannot do that. [Male, age 57 years]

Participants did not want advice from peers based on general or "medical knowledge" of type 1 diabetes; they preferred to have the opportunity to reflect on their own lives in the light of other's experiences. A 39-year-old woman pointed out that real-life experiences of others can be "the missing link" between knowledge obtained from physicians and how it can be used in their own lives.

Participant preferences for experience sharing included general and more specific topics. More general topics included worries and concerns about living with diabetes and those related to family and work. More specific topics included food, hypoglycemia, travel, sports/exercise, relationship with the doctor/nurse, use of social services, insulin pumps, etc. Participants emphasized that peer support is particularly relevant in relation to big "changes in life", for example, in family or work situations or events such as getting an insulin pump.

\section{Cohesion and collectiveness}

Participants frequently expressed that peer support can create a "safe place" arising from just being among others with type 1 diabetes. A 46-year-old man expressed this feeling in a group discussion: "Just the fact that she [another participant] 
is measuring her blood sugar right now as we speak. That is so cool. And you're thinking, wow, you have diabetes, too!" Others expressed similar feelings, such as "being on the same wavelength" and "having a mutual understanding". As a participant stated during an interview:

Diabetes and what it does to you doesn't have its own language. We don't have words to define what it feels like when you have low blood sugar. When you talk to others [referring to people who do not have diabetes] you need something to compare with, to try and explain how it is, and it's nice sometimes not having to do that. [Female, age 42 years]

Another participant, who had never met another person with type 1 diabetes before, experienced this:

To have the chance to talk about these worries, just to say them out loud and then to someone who knows exactly how it is. I experienced this the first time I was here. Me and B .... [another participant], we didn't need to explain much, with just a few words, we knew what we were talking about. We had this mutual understanding and having that experience gave me a lot. I thought ... well ... I am not alone in the world. There are others like me. [Female, age 48 years]

Several participants expressed feeling that sharing experiences with peers helped them to view the state of having diabetes as normal and created a feeling of collectiveness that they did not experience in daily life. Being similar to and understood by other participants provided support. In the words of one participant, newly diagnosed with type 1, who felt that nobody truly understood her situation: "these workshops have saved my life" (female, age 36 years).

\section{Trust and confidence}

In group discussions about preferred types of peer support, participants often used words such as "trust", "confidence", and "presence". A 56-year-old woman pointed out the necessity for a basic feeling of trust and safety among participants in a peer support program in order to address difficult topics. Another woman elaborated:

I think that sharing experiences related to more concrete things are important and maybe that is the easiest part. The more uncomfortable thoughts and questions about situations in everyday life which we confront are, perhaps, better left out until a greater level of trust is established. [Female, age 62 years]
In contrast, other participants felt that confidence naturally arose from being among others with type 1 diabetes. A 46-year-old man referred to a conversation with a woman from the workshop:

That kind of confidence you feel when you are among other people with diabetes ... I feel like I've spent many years trying to find out who I am - "diabetes-wise" and otherwise. I think that I've made a lot of progress. But at the same time there is still a lot of questions and concerns which crop up all the time. It felt safe to talk about it with her (another peer).

\section{Reciprocity and social participation}

Participants repeatedly emphasized that a natural reciprocity exists in relationships between people with type 1 diabetes and that peer support should focus on enhancing this reciprocity in the form of peer-to-peer partnerships or a group of peers in which everyone shares experiences and has the chance to reflect on their own lives with diabetes. However, participants also stated that in specific situations, such as being newly diagnosed, a mentoring relationship might be more appropriate. Participants had different perspectives about how to match peers. Some participants argued that differences in sex, age, and diabetes duration would be a barrier to reciprocity; others believed that differences would enhance the perspective on one's own life with diabetes and the possibilities for reflexivity. The workshops, for which participants were selected so as to include differences in sex, occupation, age, and diabetes duration, showed that they in fact benefited from experience sharing and mutual understanding, despite these differences. Data also showed participants' strong interest in social participation related to diabetes; they expressed interest in providing social support to others with type 1 diabetes as well as receiving support from peers. Furthermore, they showed a genuine interest in helping each other and in widening the scope of support for people with type 1 diabetes in general.

\section{Discussion}

To the best of our knowledge, ours is the first study to explore patient perspectives on the function of peer support in adult type 1 diabetes. The need for peer support arose from a feeling of diabetes-specific loneliness that was shared across differences in sex, age, diabetes duration, employment status, and marital status, and relevant peer support can create diabetes-specific social capital. The concept of diabetes-specific social capital was identified in this study; 
it emphasizes both the collective importance of experience sharing between people with type 1 diabetes and the broader need for communality related to type 1 diabetes. Furthermore, diabetes-specific social capital highlights the fact that social participation - being able to share experiences, support, and being with people with the same condition - is just as important as receiving support. Other studies in diabetes have indicated greater benefits to self-care activities from providing social support to peers than receiving support from them. ${ }^{23}$

The concepts of loneliness and social capital were identified through our empirical findings and served as a theoretical framework in the analyses. Others have identified that loneliness relates to specific types of social relationships, for example, research among adolescents has differentiated between peer-related loneliness and family-related loneliness. ${ }^{24}$ To the best of our knowledge, no previous study has explored loneliness specifically related to diabetes. However, the well-known Problem Areas in Diabetes survey incorporates one item regarding "feeling alone with diabetes". ${ }^{25}$ Our findings concerning lack of communality correspond with those of a global diabetes study (DAWN2), in which approximately one-fifth of people with diabetes felt they had been discriminated against because of their disease. ${ }^{26}$ Generally, feelings such as reciprocity, belonging, participation, high social support, and feelings of solidarity are traits of communities with high social capital. ${ }^{21,27,28}$ Sense of belonging is an important factor in health promotion, and studies of social capital have found that low social capital is related to both lower quality of life and higher morbidity. ${ }^{29-31}$ The influence of social capital has also been explored in people with diabetes but not social capital created between people with diabetes specifically. With this broader perspective, for example, trust and solidarity in the local neighborhood have been found to be associated with good glycemic control. ${ }^{32,33}$ Further research should explore whether enhancing diabetesspecific social capital can improve psychosocial and physical outcomes in people with type 1 diabetes.

From the perspective of participants, peer support is unique and in contrast to the type of diabetes peer programs that build on health professionals' understanding of support and focus on peer education. ${ }^{10,13,17,18}$ Our findings emphasize that adults with type 1 diabetes perceive the primary role of peer support as creating social networks of people who understand their mutual situation in a way that other social networks do not. Health care professionals cannot create or provide diabetes-specific social capital - and peer support cannot substitute for support from health care professionals.
However, our findings confirm our initial description of the aim of peer support in chronic illness. ${ }^{14}$

Our findings also highlight the fact that few studies have focused on peer support targeting people with type 1 diabetes, although it seemed to be very much needed. Some participants had never met another person with type 1 diabetes; having the opportunity to do so was very meaningful to them. Our findings included differing perspectives on how to best match peers to provide mutual support. Although some participants stated that peers needed to have similar characteristics, the workshops indicated that the possibility of enhancing diabetes-specific social capital existed within the group despite large differences between participants. Further research is needed in relation to what combination of participant characteristics in peer support best creates diabetes-specific social capital.

Strengths of our study include continuous analyses during data collection, allowing reflection and validation among participants and co-researchers. The inclusion of different settings is also a strength. ${ }^{34}$ The data across settings were very similar; participants in the two groups even used similar wording, such as the request for "real dialogue" and "support in life transitions". They also articulated "sterile answers" from professionals and "real-life experiences" in both settings. The comparison of the two settings indicated that data saturation was reached.

The use of group discussions and participatory methods revealed dimensions of understanding that might have remained untapped in more conventional data collection techniques. ${ }^{35,36}$ For example, testing different peer support methods enabled reactions to concrete peer relations and revealed unmet and, for some participants, unknown needs. The use of various methods and a diverse sample is believed to increase the robustness of the results. ${ }^{34}$

A limitation of our study is that participants might have chosen to participate in the study due to positive preferences for peer support. However, some participants were recruited based on earlier involvement in a study that was unrelated to peer support. Group discussions and interviews may have constrained participants from sharing views that diverged from the group consensus. We found a tendency toward more openness and in-depth descriptions of personal experiences with regard to feelings of diabetes-specific loneliness in individual interviews rather than in group interviews. ${ }^{37}$

With the use of a theoretical framework and the diverse empirical data, the findings of this study seem relevant and highly likely to be transferable to other adults with type 1 diabetes in Denmark, as well as in similar countries. It is 
also likely that the feeling of diabetes loneliness and the need of diabetes-specific social capital are present among people with type 1 diabetes in other countries as well, as the findings of our studies are grounded in theoretical constructs and relate to existing literature as discussed earlier. However, potential differences, including cultural differences, in subgroups need to be explored. The study does not provide evidence about the prevalence of diabetes loneliness or the need for diabetes-specific social capital. Differences in prevalence of adults with type 1 diabetes in different subgroups need further exploration. Furthermore, research into effects of enhancing diabetes-specific social capital is needed, for example, in relation to the potential to decrease diabetes distress and improve self-management behaviors. Our study indicates a substantial need for peer support among adults with type 1 diabetes, focusing on the creation and strengthening of diabetes-specific social capital as a response to a shared feeling of diabetes-specific loneliness. Methods and settings for enhancing diabetesspecific social support through peer support need further exploration and testing in collaboration with people with type 1 diabetes.

\section{Acknowledgments}

We thank all the participants for their participation in workshops and individual interviews. LEJ and IW are employed by Steno Diabetes Center A/S, a research hospital working in the Danish National Health Service and owned by Novo Nordisk A/S. Steno Diabetes Center receives part of its core funding from unrestricted grants from the Novo Foundation and Novo Nordisk A/S.

\section{Disclosure}

The authors report no conflicts of interest in this work.

\section{References}

1. Joensen LE, Tapager I, Willaing I. Diabetes distress in type 1 diabetes a new measurement fit for purpose. Diabet Med. 2013;30(9): 1132-1139.

2. Trief PM, Sandberg JG, Dimmock JA, Forken PJ, Weinstock RS. Personal and relationship challenges of adults with type 1 diabetes: a qualitative focus group study. Diabetes Care. 2013;36(9):2483-2488.

3. Joensen LE, Almdal TP, Willaing I. Type 1 diabetes and living without a partner: psychological and social aspects, self-management behaviour, and glycaemic control. Diabetes Res Clin Pract. 2013;101(3):278-285.

4. Lloyd CE, Wing RR, Orchard TJ, Becker DJ. Psychosocial correlates of glycemic control: the Pittsburgh epidemiology of diabetes complications (EDC) Study. Diabetes Res Clin Pract. 1993;21(2-3):187-195.

5. Kawachi I, Berkman LF. Social ties and mental health. J Urban Health. 2001;78(3):458-467.

6. Kawachi I. Social capital and health. In: Bird C, Conrad P, Fremont AM, Timmermans S, editors. Handbook of Medical Sociology. 6th ed. Nashville, TN: Vanderbilt University Press; 2010:18-32.
7. Berkman LF, Glass T, Brissette I, Seeman TE. From social integration to health: Durkheim in the new millennium. Soc Sci Med. 2000;51(6): 843-857.

8. Joensen LE, Almdal TP, Willaing I. Associations between patient characteristics, social relations, diabetes management, quality of life, glycaemic control and emotional burden in type 1 diabetes. Prim Care Diabetes. 2016;10(1):41-50.

9. Heisler M. Different models to mobilize peer support to improve diabetes self-management and clinical outcomes: evidence, logistics, evaluation considerations and needs for future research. Fam Pract. 2010;27(suppl 1):i23-i32.

10. World Health Organization. World Health Report: Peer Support Programs in Diabetes. Geneva: WHO; 2008.

11. van Dam HA, van der Horst FG, Knoops L, Ryckman RM, Crebolder HF, van den Borne BH. Social support in diabetes: a systematic review of controlled intervention studies. Patient Educ Couns. 2005;59(1):1-12.

12. Harkness E, Macdonald W, Valderas J, Coventry P, Gask L, Bower P. Identifying psychosocial interventions that improve both physical and mental health in patients with diabetes: a systematic review and metaanalysis. Diabetes Care. 2010;33(4):926-930.

13. Dale JR, Williams SM, Bowyer V. What is the effect of peer support on diabetes outcomes in adults? A systematic review. Diabet Med. 2012; 29(11):1361-1377.

14. Dennis CL. Peer support within a health care context: a concept analysis. Int J Nurs Stud. 2003;40(3):321-332.

15. Peers for Progress (homepage). University of North Carolina at Chapel Hill. Available at http://peersforprogress.org/. Accessed April 29, 2016.

16. Fisher EB, Ayala GX, Ibarra L, et al; Peers for Progress Investigator Group. Contributions of peer support to health, health care, and prevention: papers from peers for progress. Ann Fam Med. 2015;13(suppl 1): S2-S8.

17. Simmons D, Bunn C, Cohn S, Graffy J. What is the idea behind peerto-peer support in diabetes? Diabetes Manage. 2013;2(1):61-70.

18. Brownson CA, Heisler M. The role of peer support in diabetes care and self-management. Patient. 2009;2(1):5-17.

19. Meyer J. Qualitative research in health care. Using qualitative methods in health related action research. BMJ. 2000;320(7228):178-181.

20. Malterud K. Systematic text condensation: a strategy for qualitative analysis. Scand J Public Health. 2012;40(8):795-805.

21. Putnam RD. Bowling Alone: The Collapse and Revival of American Community. New York, NY: Simon \& Schuster; 2000.

22. Peplau L. Loneliness research: basic concepts and findings. In: Sarason I, Sarason B, editors. Social Support: Theory, Research, and Applications. Boston: Martinus Nijhoff Publishers; 1985:269-286.

23. Heisler M, Piette JD. "I help you, and you help me": facilitated telephone peer support among patients with diabetes. Diabetes Educ. 2005; 31(6):869-879.

24. Lasgaard M, Goossens L, Bramsen RH, Trillingsgaard T, Elklit A. Different sources of loneliness are associated with different forms of psychopathology in adolescence. J Res Pers. 2011;45(2):233-237.

25. Polonsky WH, Anderson BJ, Lohrer PA, et al. Assessment of diabetesrelated distress. Diabetes Care. 1995;18(6):754-760.

26. Nicolucci A, Kovacs Burns K, Holt RI, et al; DAWN2 Study Group. Diabetes attitudes, wishes and needs second study (DAWN2): crossnational benchmarking of diabetes-related psychosocial outcomes for people with diabetes. Diabet Med. 2013;30(7):767-777.

27. Nieminen T, Martelin T, Koskinen S, Aro H, Alanen E, Hyyppa MT. Social capital as a determinant of self-rated health and psychological well-being. Int J Public Health. 2010;55(6):531-542.

28. Ferlander S. The importance of different forms of social capital for health. Acta Sociol. 2007;50(2):115-128.

29. Murayama H, Fujiwara Y, Kawachi I. Social capital and health: a review of prospective multilevel studies. J Epidemiol. 2012;22(3):179-187.

30. Kawachi I, Kennedy BP, Glass R. Social capital and self-rated health: a contextual analysis. Am J Public Health. 1999;89(8):1187-1193. 
31. Kawachi I, Kennedy BP, Lochner K, Prothrow-Stith D. Social capital, income inequality, and mortality. Am J Public Health. 1997;87(9): 1491-1498.

32. Long JA, Field S, Armstrong K, Chang VW, Metlay JP. Social capital and glucose control. J Community Health. 2010;35(5):519-526.

33. Farajzadegan Z, Jafari N, Nazer S, Keyvanara M, Zamani A. Social capital - a neglected issue in diabetes control: a cross-sectional survey in Iran. Health Soc Care Community. 2013;21(1):98-103.

34. Patton MQ. Qualitative Research and Evaluation Methods. Thousand Oaks, CA: Sage Publications; 2002.
35. Lavie-Ajayi M. "I didn't know I was isolated until I wasn't isolated any more": the use of groups in qualitative psychology research. Qualitative Inquiry. 2014;20(2):175-182.

36. Kitzinger J. Qualitative research. Introducing focus groups. BMJ. 1995;311(7000):299-302.

37. Kvale S. Interviews - An Introduction to Qualitative Research Interviewing. Thousand Oaks, CA: Sage Publications; 1996.

\section{Publish your work in this journal}

Patient Preference and Adherence is an international, peer-reviewed, open access journal that focuses on the growing importance of patient preference and adherence throughout the therapeutic continuum. Patient satisfaction, acceptability, quality of life, compliance, persistence and their role in developing new therapeutic modalities and compounds to optimize clinical outcomes for existing disease states are major areas of interest for the journal. This journal has been accepted for indexing on PubMed Central. The manuscript management system is completely online and includes a very quick and fair peer-review system, which is all easy to use. Visit http://www. dovepress.com/testimonials.php to read real quotes from published authors.

\footnotetext{
Submit your manuscript here: http://www.dovepress.com/patient-preference-and-adherence-journal
} 